\title{
Quanto mais me bates, menos gosto de mim - abordagem da violência doméstica em Cuidados de Saúde Primários
}

Alexandra Pina*

\section{RESUMO}

Introdução: A violência doméstica é uma epidemia que tem estado presente desde sempre na sociedade, sendo transversal a todas as classes socioeconómicas e culturais ou educacionais. O médico da família tem tradicionalmente dificuldade em gerir estas situações, ficando dividido entre ter uma atitude de apoio e escuta passiva ou em tomar alguma ação no sentido de capacitar a vítima das opções que existem na comunidade para a apoiar.

Descrição do caso: Fiona, 37 anos, apresenta um contexto socioeconómico adverso e alterações da dinâmica familiar recente. Recorre a consulta programada referindo ter sido vítima recente de maus tratos físicos conjugais, após semanas de intimidação, violência emocional, verbal e psicológica e ameaças de morte. Pediu auxílio à polícia mas recusou o apoio imediato de emergência social para si e filho de sete anos, que incluía ficar numa Casa-Abrigo. Esta recusa possibilitou um contacto do agressor com o filho, influenciando negativamente a sua relação com Fiona. Perante o desespero da doente, foi agendada nova consulta para acompanhar a evolução da situação. A equipa de saúde foi ativada, visando a construção de uma proposta de Plano de Prevenção Terciária da Violência Doméstica. A capacitação da utente e dissecção das alternativas de futuro e do apoio comunitário disponível culminaram no consentimento da mesma em reingressar no circuito de proteção de vítimas e ir com o filho para uma Casa-Abrigo.

Comentário: O caso explora a forma como o papel do Médico de Família na gestão de situações de violência doméstica pode ser mais ativa no sentido de capacitar as vítimas e incentivar a sua segurança, fazendo-as conhecer os seus direitos ou fornecendo referências apropriadas para que possam procurá-las. O trabalho integrado da equipa de saúde é fundamental para uma orientação global e mais efetiva da vítima.

Palavras-chave: Violência doméstica; Equipa de Saúde; Capacitação.

\section{INTRODUÇÃO}

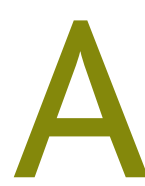

violência doméstica é um crime público que se encontra ainda demasiado presente na nossa sociedade. $\mathrm{O}$ aumento do número de denúncias decorrerá, em parte, da maior consciência das vítimas em relação aos seus direitos. ${ }^{1}$ Trata-se de uma designação que engloba todo o tipo de agressões, físicas ou psicológicas, que existam no seio de uma relação emocional/familiar, atingindo qualquer elemento dessa relação, ${ }^{2}$ e cerca de um quarto dos casais portugueses admite ter vivido uma situação de vio-

* Interna de Medicina Geral e Familiar na Unidade de Saúde Familiar Horizonte, ACES de Matosinhos lência deste tipo. ${ }^{3}$

As mulheres são as vítimas mais frequentes, estimando-se que «a violência contra as mulheres no espaço doméstico é a maior causa de morte e invalidez entre mulheres dos 16 aos 44 anos, ultrapassando o cancro, acidentes de viação e até a guerra.» ${ }^{4}$

No entanto, face a este tipo de situações de violência, foi constatado, num inquérito nacional de 1995, que a maioria das mulheres se limita meramente a ter uma reação passiva à agressão (78\%), e que só $1 \%$ das vítimas recorre aos tribunais ou pede auxílio à polícia. ${ }^{5}$

No que respeita aos cuidados de saúde, esta situação entra dentro do gabinete do Médico de Família (MF) com a vítima, frequentemente escondida atrás de um 
muro de vergonha e de auto-culpabilidade, queixas físicas inespecíficas ou desculpas relacionadas com acidentes domésticos repetidos. Um estudo de 2005 sobre Violência Física Conjugal na Mulher, realizado em Cuidados de Saúde Primários, identificou uma prevalência de 20,5\%, independentemente da idade, estado civil, ou nível socioeconómico da vítima. ${ }^{6}$

Frequentemente, mesmo quando as marcas físicas ou psicológicas levantam a suspeita deste crime, gera-se uma "conspiração do silêncio» perante estas situações, na qual colabora a própria vítima, que frequentemente tem pouca consciencialização da natureza criminal e vive uma ambiguidade de sentimentos que não a deixam agir. Existe ainda uma certa tolerância e cumplicidade para com o homem quando este é o agressor. Porém, quando há o gut feeling de um desfecho fatal, existirão mais medidas que o Médico de Família poderá adotar, de modo a procurar capacitar a vítima e proteger os elementos da família que segue.

\section{DESCRIÇÃO DO CASO}

\section{Identificação}

Fiona é uma utente de 37 anos, que consentiu a transposição da sua história, garantindo-se a confidencialidade.

De raça caucasiana e natural do Alentejo, reside numa cidade do norte do país há 19 anos e tem o $6 .^{\circ}$ ano de escolaridade. Trabalhava num «restaurante» gerido pela família.

Como antecedentes pessoais apresentava registos de distimia, ansiedade e baixa autoestima. Não existiam antecedentes familiares de relevo.

Pertencia a uma classe de Graffar média-baixa e o seu agregado familiar era constituído pelo marido, com quem está casada desde os 17 anos, e pelos dois filhos de ambos (rapazes com 19 e 7 anos), encontrando-se na fase $\mathrm{V}$ do ciclo de Duvall. $\mathrm{O}$ único outro contacto relevante é a mãe, que mora no Alentejo.

Não existiu possibilidade para fazer entrevista e avaliação familiar por limitação de tempo e urgência na resolução do caso clínico.

\section{Contexto familiar e social}

Em julho de 2011 o filho mais velho abandona a casa e trabalho no restaurante, em conflito com o pai, quando se descobre que este tem uma relação extraconju- gal e um filho com a outra companheira.

Na sequência desta situação, o marido abandonou também a casa.

Fiona passou a gerir as dívidas da casa e do restaurante sozinha, o que ainda dificultou mais a situação económica do agora agregado monoparental (ela e o filho mais novo).

\section{História da doença atual}

Em setembro de 2011, numa consulta de planeamento familiar e vigilância oncológica, aborda-se a situação familiar atual e a utente refere estar «cansada e triste, com medo de não ter capacidade para gerir as dívidas e as despesas da casa e restaurante». É disponibilizado apoio em nova consulta, sugerindo-se a realização de uma avaliação familiar, mas Fiona refere estar atualmente muito ocupada com o trabalho e fica de agendar novo contacto quando tiver possibilidade.

Em fevereiro de 2012, Fiona regressa a uma consulta na USF e refere ter sido vítima de violência doméstica física pelo marido há 15 dias, na sequência de semanas de insistência para reatarem o casamento, associada a persistente violência psicológica, incluindo ameaças de morte. Mesmo no local de trabalho tornaram-se persistentes os insultos a Fiona e aos clientes, assim como demonstrações de ciúme.

Após ter contactado a polícia, foi ativada a linha 144 (Emergência Social), que a encaminhou para o serviço local «Primeiro Passo», um Centro de Atendimento aVítimas deViolência da delegação da Cruz Vermelha Portuguesa, e alertou a Comissão de Proteção de Crianças e Jovens por haver um menor envolvido. Nesse serviço de apoio à vítima, foram realizados acompanhamento psicológico e aconselhamento jurídico e foi aconselhada a abandonar a casa e fechar o restaurante. Recusou a resposta de emergência imediata que lhe ofereceram, e que incluía ser alojada numa Casa Abrigo. Preferiu pedir a uma amiga para a acolher em sua casa com o filho.

Como o ex-companheiro conhecia esta amiga, passou a ir ver a criança todos os dias, manipulando-a psicologicamente para insultar e duvidar da mãe. Até o filho mais velho foi influenciado pelo pai e encontrava-se solidário para com este.

Fiona contemplou o suicídio várias vezes e a sua baixa autoestima encontrava-se ainda mais exacerbada. 
Apesar de já ter adquirido algum conhecimento dos seus direitos no primeiro contacto com a APAV, não conseguia evitar sentimentos de ambiguidade emocional, vergonha, auto-culpabilidade, medo e impotência.

Foi agendada uma nova consulta para a semana seguinte, para apoio da utente e acompanhamento da situação familiar. Este intervalo de tempo serviu como espaço de reflexão relativamente ao caso clínico e de interrogação relativamente à forma como deveria ser abordado.

Apesar de se tratar de uma consulta médica, este caso era um exemplo também de uma velha questão social de um crime público (artigo 152. ${ }^{\circ}$ do Código Penal Português $)^{7}$ que como cidadão se tem a obrigação de denunciar. Esta mulher estava a ser vítima de Violência Conjugal com vitimação múltipla, tendo sofrido maus tratos físicos, intimidação, maus tratos emocionais, verbais e psicológicos, ameaças, e recurso ao privilégio masculino. ${ }^{8}$

Uma vez que a situação já tinha sido denunciada, e como médico de toda a família, surgiu o dilema entre adotar uma atitude passiva de apoio ou decidir investir em capacitar a utente para outras soluções. Tratando-se o marido de um indivíduo que teríamos dificuldade em persuadir no sentido da mudança de atitudes e dada a perceção de que se trataria de uma situação grave, optou-se por discutir este problema com a equipa de saúde, e pedir a colaboração da assistente social.

Procedeu-se ao contacto com o local onde a utente tinha sido primeiramente observada após a ocorrência, para se averiguar se o gut feeling corresponderia à realidade. Foi contactada a «Primeiro Passo», e os profissionais que tinham apoiado Fiona ainda se recordavam perfeitamente da situação, mesmo após terem passado duas semanas, porque também tinham ficado apreensivos com a decisão da utente. Aproveitou-se para se discutir com esses profissionais as opções e possibilidade de a reintegrar no circuito de apoio à vítima, caso aceitasse, e foi confirmada a disponibilidade.

Antes do contacto com Fiona, foi realizado um exercício de avaliação do contexto e das suas necessidades conhecidas: não existia possibilidade de apoio familiar próximo e não havia rede económica de suporte; o apoio por pessoas conhecidas pelo marido revestia-se de perigos paralelos; e tornava-se clara a necessidade de cuidados especializados e regulares a nível psicológico, quer para si, quer para o filho.
O objetivo estabelecido pela equipa foi no sentido de tentar capacitar a utente dos seus direitos e rever o seu contexto atual, de modo a promover a adesão a um Plano de Prevenção Terciária da Violência Doméstica, ${ }^{8}$ que incluísse as vertentes de reabilitação, reintegração na sociedade e redução dos traumas psicológicos e incapacidade a longo prazo associada com a violência. Este apoio poderia ser realizado, com mais dificuldade, em ambulatório, ou poderia ser facilitado e protegido, caso aceitasse a integração num dos Centros de Apoio especializado.

A consulta de reavaliação agendada pelo prestador de cuidados foi realizada com a colaboração da Assistente Social. Mantinham-se as ameaças, a perseguição e tinha-se agravado a incapacidade para gerir os sentimentos e reações do filho, que já apresentava comportamentos agressivos para com Fiona.

A Equipa colocou em prática o plano pré-estabelecido, e debateram-se os prós e contras de manter a situação atual, para si mas também para o seu filho, tendo em conta o seu contexto sócio-familiar, económico e emocional. A utente decidiu aceitar ajuda para reativar novo contacto com a «Primeiro Passo». Foi confirmada a disponibilidade de integrar Fiona e o filho numa Casa Abrigo, de modo a poder construir-se um plano de apoio para ambos (Z45, Z58). A dificuldade em gerir o comportamento do filho mais novo foi a principal força motriz para a mudança de atitude da utente.

\section{COMENTÁRIO}

A abordagem realizada neste caso de violência doméstica partiu da perceção da sua gravidade pelo MF, que entendeu ser seu dever capacitar a utente dos seus direitos, com o apoio da equipa de saúde.

O seu raciocínio clínico implicou uma visão da realidade biopsicossocial, emocional e espiritual da utente, de modo a ajudá-la a desenhar um plano de prevenção terciária da violência doméstica que beneficiaria em ser cumprido numa instituição especializada.

O papel do Médico de Família passará, mais do que oferecer o ombro amigo, por apoiar nas decisões e ouvir as queixas das vítimas. É necessário compreender a dinâmica da Violência Conjugal, questionar sobre a existência dos vários tipos de agressão para avaliar o risco/gravidade associado e, pelo menos, incentivar a segurança dos utentes e fazê-los conhecer os seus direi- 
QUADRO I. Contactos e apoios na comunidade para vítimas de violência.

Linha Nacional de Emergência: 112

Esquadra local PSP/GNR/PJ ou

Serviços do Ministério Público

Gabinetes/Institutos de Medicina

Legal e de Consulta Jurídica

Gabinetes de Apoio à Vítima locais ${ }^{9}$

Inforço de Inação às vítimas

de VD - 800202148

Linha Nacional de Emergência

Social: 144

Site APAV - http://www.apav.pt

Site Comissão para a cidadania e

igualdade de género (CIG)
1. Pedir socorro e/ou procurar refúgio e auxílio de outras pessoas (poderão servir de testemunhas) e depois contactar o 112.

Queixa e contacto após episódio de violência. Encaminha os casos comunicados pela PSP, GNR ou Tribunais para a Segurança Social

Também é possível apresentar queixa nas Delegações do Instituto Nacional de Medicina Legal e nos Gabinetes médico-legais a funcionar continuamente em muitos hospitais. Requisição de apoio médico-legal e judicial.

Rede de Voluntariado com serviços variavéis: apoio emocional, jurídico, psicológico e social à vítima de crime. Atendimento e o acompanhamento personalizado, confidencial e gratuito.

Linha gratuita de Informação da responsabilidade da Comissão para a Igualdade e para os Direitos das Mulheres (CIDM), que funciona $24 \mathrm{~h} / 7$ dias por semana. A CIDM oferece ainda atendimento direto nos Gabinetes de Lisboa e Porto.

Serviço nacional público gratuito da Segurança Social, 24 h / 7 dias por semana - proteção e salvaguarda da segurança dos cidadãos em situação de Emergência social (grupos prioritários: Crianças e jovens em perigo; Idosos em situação de abandono; Pessoas vítimas de violência doméstica; Pessoas em situação de sem-abrigo). Articulam com os organismos necessários para dar uma resposta social imediata e assegurar a acessibilidade a um posterior acompanhamento social, numa perspetiva de inserção e autonomia.

Para além da informação disponibilizada é possível realizar uma queixa eletrónica ao Ministério da Administração Interna.

Listagem das estruturas de atendimento a vítimas de violência doméstica por distrito e por concelho. In: http://195.23.38.178/cig/portalcig/bo/documentos/Estruturas_atendimento _Concelho.pdf tos ou fornecer referências apropriadas para que possam procurá-las.

No Quadro I listam-se alguns dos contactos e locais na comunidade que se julgam importantes para uma melhor orientação das vítimas deste crime público, e que podem facilmente ser sugeridos pelo médico de família, como gestor da saúde dos seus utentes, mas também como cidadão.

É compreensível que para estas vítimas dificilmente há finais felizes, mas o relato deste caso pretende relembrar que é possível que possamos tentar contribuir para que os desfechos destas situações sejam menos dramáticos do que aqueles que nos acabam por chegar através dos meios de comunicação social, em que muitas vidas vão ficando pelo caminho.

\section{AGRADECIMENTOS}

A autora agradece o apoio e colaboração da Assistente Social do ACES de Matosinhos, Dr. ${ }^{\text {a }}$ Sandra Ferreira, que foi fundamental na gestão do caso relatado e na obtenção do consentimento informado da utente, por contacto com as instâncias de apoio à vítima onde esta se encontra atualmente.

\section{REFERÊNCIAS BIBLIOGRÁFICAS}

1. Associação Portuguesa de Apoio à Vítima. Relatório Anual 2011 - Estatísticas APAV. Disponível em: http://apav.pt/apav_v2/images/pdf/Estatisticas_APAV_RelatorioAnual_2011.pdf [acedido em 15/12/2012].

2. World Health Organization. La violencia, un problema mundial de salud pública. Capítulo 1. Informe mundial sobre la violencia y la salud. Disponível em: http://www.paho.org/Spanish/AM/PUB/capitulo_1.pdf [acedido em 15/12/2012].

3. Machado C. Violência nas famílias portuguesas: um estudo representativo na região norte. Psychologica (Coimbra) 2005; 40: 173-94.

4. Plano Nacional contra a Violência Doméstica. Resolução do Conselho de Ministros n 55/99, de 27 de maio. Disponível em: http://app.parlamento.pt/violenciadomestica/conteudo/pdfs/legislacao/rcm551999 .pdf [acedido em 15/12/2012].

5. Lourenço N, Lisboa M, Pais E. Inquérito Nacional "Violência Contra as Mulheres". Lisboa: Universidade Nova de Lisboa/Comissão para a Igualdade e para os Direitos das Mulheres; 1995.

6. Coelho P. Violência Conjugal - Violência física conjugal nas mulheres 
que recorrem aos cuidados de saúde primários. Rev Port Clin Geral 2005 jul-ago; 21 (4): 343-51.

7. Portugal. Código Penal. Art. $152^{\circ}$ (Violência doméstica).

8. Centers for Disease Control and Prevention. The Social-Ecological Model: a Framework for Prevention. Disponível em: http://www.cdc.gov/ ViolencePrevention/overview/social-ecologicalmodel.html [acedido em 28/11/2012].

9. Estruturas de Atendimento a Vítimas de Violência Doméstica. Disponível em: http://195.23.38.178/cig/portalcig/bo/documentos/Estruturas_atendimento_Concelho.pdf [acedido em 15/12/2012].

\section{FINANCIAMENTO}

Este estudo não recebeu qualquer financiamento externo.

\author{
ENDEREÇO PARA CORRESPONDÊNCIA \\ Alexandra Pina \\ Rua Carlos Alberto Morais, 122D, $11 .^{\circ}$ esq. ${ }^{\circ}, 4450-349$, Leça da Palmeira \\ E-mail: amspina@gmail.com
}

Recebido em 26/12/2012

Aceite para publicação em 23/05/2013

\section{CONFLITOS DE INTERESSE}

A autora declara não possuir qualquer tipo de conflito de interesses.
Artigo escrito ao abrigo do novo acordo ortográfico.

\section{ABSTRACT}

\section{THE MORE YOU HIT ME, THE LESS I LOVE MYSELF...}

Introduction: Domestic violence is an epidemic that is present in society across all socio-economic, cultural and educational groups. Family physicians experience difficulty in managing these situations, torn between a passive, supportive attitude and action to empower victims with support in the community.

Case description: Fiona, aged 37, came from a deprived socio-economic background and had recent changes in her family. She came to an appointment and revealed that she had recently been a victim of physical abuse by her spouse after weeks of intimidation, emotional, verbal and psychological abuse, and death threats. She called the police for help and was referred to community institutions specialized in managing these situations, but she refused to stay in a shelter with her 7 year-old son. This situation allowed regular contact between the child and his father (the abuser), resulting in a negative influence on the child's relationship with Fiona. Given the desperate situation of the patient, a follow-up visit was arranged to monitor developments. The perception of increased risk led the healthcare team to build a tertiary prevention plan for domestic violence to be presented to the patient. Enablement of the patient, including providing knowledge of the community support programs available, allowed her to agree to go to live in a shelter with her son.

Comment: This case explores the role of the family doctor in the management of domestic violence. A more active approach, aiming to empower victims, promoting their safety, making them aware of their rights, and providing appropriate referral to community resources with specialized help for these situations is required. Integrated effort by the healthcare team is critical for the design of effective guidance to victims.

Key-words: Domestic violence; Healthcare team; Enablement. 